\title{
Anger Management among Medical Undergraduate Students and Its Impact on Their Mental Health and Curricular Activities
}

\author{
Gayathri S. Prabhu, ${ }^{1}$ Joanne Tam Min Yen, ${ }^{2}$ Jonas John Posko Amalaraj, \\ Eugene Tan Yie Jone, ${ }^{2}$ and Naveen Kumar ${ }^{1}$ \\ ${ }^{1}$ Department of Anatomy, Melaka Manipal Medical College, Manipal University, Manipal Campus, Manipal 576104, India \\ ${ }^{2}$ Melaka Manipal Medical College, Manipal University, Manipal Campus, Manipal 576104, India \\ Correspondence should be addressed to Naveen Kumar; naveentonse@gmail.com
}

Received 29 April 2016; Revised 7 July 2016; Accepted 12 July 2016

Academic Editor: Shu-Sheng Liaw

Copyright (C) 2016 Gayathri S. Prabhu et al. This is an open access article distributed under the Creative Commons Attribution License, which permits unrestricted use, distribution, and reproduction in any medium, provided the original work is properly cited.

Background. This study was intended to determine the practice of students in good anger management skills and to what extent their anger can affect their studies, work, and social interactions. In this study the relationship between anger management and the effects on the mental health of medical students was evaluated. A survey was also done to determine duration of the feeling of anger which lasts among medical students and its consequences. Materials and Methods. A newly developed questionnaire was utilized which included a simplified version of the Novaco Anger Scale and Provocation Inventory and the modified Patient Health Questionnaire 9 (to measure the mental health). Results. The data suggests that although students with high anger tendencies display poor mental health, there is no lowering of the mental health/PHQ-9 score as the anger management technique's effectiveness rises. "Friends" was cited as the major triggering factor for anger, whereby the feelings can last for up to a day and somewhat affect their concentration on normal activities. Conclusion. When anger is suppressed and not let out, it can be an underlying factor for anxiety and depression. Therefore, more emphasis needs to be placed on educating students on how to manage their anger especially in a stressful environment away from home.

\section{Introduction}

Anger is one of the most prevalent behavioral problems among the youth and those around them. Some theorists believe that anger is a maladaptive attempt at coping with a stressful environment, resulting in greater conflict and personal discomfort [1] However, recent conceptualizations have focused on anger as an adaptive mechanism for dealing with obstructed goals and perceived threats [2], with healthy anger being differentiated from unhealthy anger in terms of how successfully the emotion serves the basic needs of the person. When anger is suppressed and not let out, it can be an underlying factor for anxiety and depression. Furthermore, relationships may be affected and thinking and behavior patterns may be altered. This becomes a major hindrance towards rational thinking among society which leads to undesirable consequences. Anger can be linked to problems such as alcohol and substance abuse, emotional and physical abuse, crime, loss of concentration, poor sleeping patterns, and feeling of insecurity and self-harm. While there is no direct cure for anger, managing it can do a lot of good. Anger management training can decrease the aggressive behavior of at-risk students in the short-term. Students trained in anger management have been found to decrease their disruptive and aggressive behaviors both at home and in the classroom and display greater self-control [3].

In a previous study, differences between people with potentially dysfunctional anger problems and people without such problems were investigated in two groups: college students and people mandated to undergo anger management treatment. College students were compared to people in anger management treatment because people in treatment have been deemed to have problem in anger [4]. High anger participants reported different coping styles compered to low anger participants, utilizing more antisocial and aggressive action but less cautious action while college participants tended to 
seek social support more frequently than participants in the anger management group [5]. These findings were consistent with previous literature on anger. In relation to that, not much research has been done on Malaysian medical undergraduate students based solely upon their anger management skills and mental health. Therefore, by conducting this research we were aiming to focus on medical college students as their lifestyle is comparatively more stressful than ordinary college goers. This study was carried out to see how their anger management skills can solely affect their psychological profile on a daily basis. Through this study we intended to reveal how well medical students manage their anger amidst other external stressful stimuli and how significantly anger affects their lives.

\section{Materials and Methods}

A cross-sectional survey was done using questionnaire. The study subjects were of 2 nd year Bachelor in Medicine and Bachelor in Surgery (MBBS) students of Melaka Manipal Medical College (MMMC), Manipal, India. All the participants were of Malaysian origin with an average age group being 19 years (ranging from 18-20 yrs). The study subjects were selected randomly irrespective of gender specification. Total of 157 students from two different semesters were involved in this study. A newly developed questionnaire was introduced in this study. A simplified version of the Novaco Anger Scale and Provocation Inventory [6] and the modified Patient Health Questionnaire- (PHQ-) 9 were incorporated in the questionnaire. The questionnaire had closed (in 5-point Likert scale) and open ended questions. This modified questionnaire was scrutinized and validated by the institutional faculties who are qualified medical educationists. The reliability of the instrument used herein was as applicable as referred Novaco Anger Scale and Provocation Inventory as mentioned by Novaco [6]. The questionnaire was distributed to the students and asked to respond to it after taking informed consent. Institutional ethical clearance was obtained before performing the current cross-sectional study.

Data Analysis. The total of the points accumulated by the respondents answering the scales ( 1 to 5 ) for each question were tabulated in percentage form. A correlation of data was made based on the anger tendency scores and anger management scores with the mental health scores (based on the modified PHQ-9 scores) statistically by using SPSS software (version 15). Significant responses on anger tendencies and their management were tabulated in bar diagrams. Individual data analysis of source of anger, effects of anger, and duration of anger among medical students were tabulated in the form of bar diagrams and pie charts.

\section{Results}

3.1. Individual Data Analysis. Based on the data, $70 \%$ of students (111 students) admitted that they have bad temper on an "occasional" basis. Moreover, only 6 (3\%) students said that they would "never" pretend to suppress or tolerate their emotions [Figure 1]. $62 \%$ of the students on the other hand

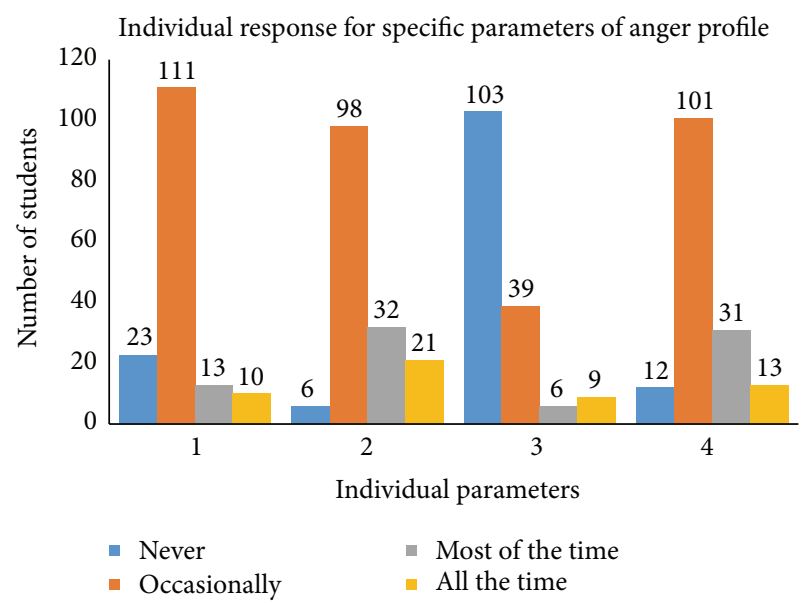

FIGURE 1: Graphic representation on individual responses for specific items of anger profile. (1) Have a bad temper; (2) pretend to suppress and tolerate emotions when angry; (3) dealing with anger by bad-eating habits/alcohol/smoking/drugs; (4) easily frustrated when machines or applications do not work.

gave the median score of "occasionally" and "often" when it comes to suppressing and tolerating their anger. However, the rest of the students exhibit poor anger expressions skills, whereby $20 \%$ of them (32 students) said that they suppress their anger and tolerate it "most of the time."

An enormous majority of students (66\%) said that they would "never" deal with anger by any of the mentioned means expressed in the questionnaire, while $25 \%$ do so "occasionally" and "often." But $6 \%$ of students resort to negative habits "all the time." Furthermore, a total of $64 \%$ of students gave a score of "occasionally" and "often" when it comes to how frequently they get frustrated. $20 \%$ said that they get frustrated most of the time, while $8 \%$ said all the time. Besides that, a huge majority (117) of students (75\%) said that they will "never" hurt themselves. Only 4 (2\%) students admitted that they will consider to hurt themselves "all the time." About 51 students (32\%) said that they will never cry when angry. 69 students (44\%) said they will "cry" "occasionally" or "often." But $15 \%$ of (23) students prefer to cry "all the time" when they are angry [Figure 2].

With 5 being the highest score, overall compilation of scores given by students showed the highest total score for source of anger being from friends, followed by self and others. Family contributes the least to the source of anger [Figure 3].

Results of frequency of anger indicated that when angry, the feelings of anger can last up to a day for almost half (49\%) of all the respondents. Meanwhile, $31 \%$ of them said that it would last for a minute to an hour. 25 students (16\%) said that the anger affects them for almost a week, while 6 students (4\%) stated that the feelings of anger would last for more than week or maybe months [Figure 4].

$23 \%$ of medical students said that anger does not interfere with their work, study, or relationships at all. A huge majority, summing up to 102 students (65\%), stated that they found it "somewhat difficult" to concentrate on their work, study, and 


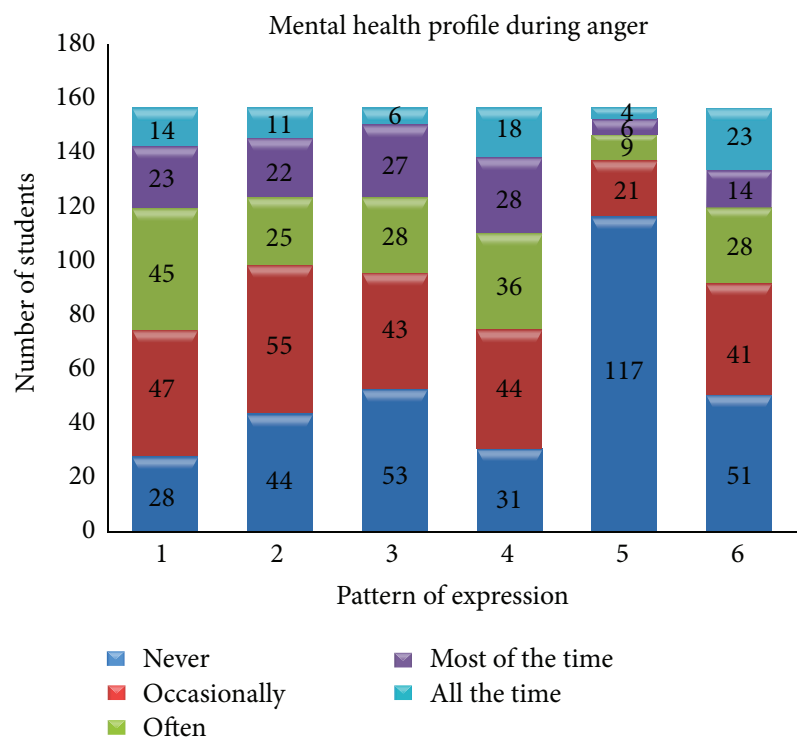

FIGURE 2: Students expression pattern in anger management. (1) Hopelessness and anxiety; (2) problems in sleeping; (3) disturbances in appetite; (4) self-isolation; (5) thinking of self-hurting; and (6) crying.

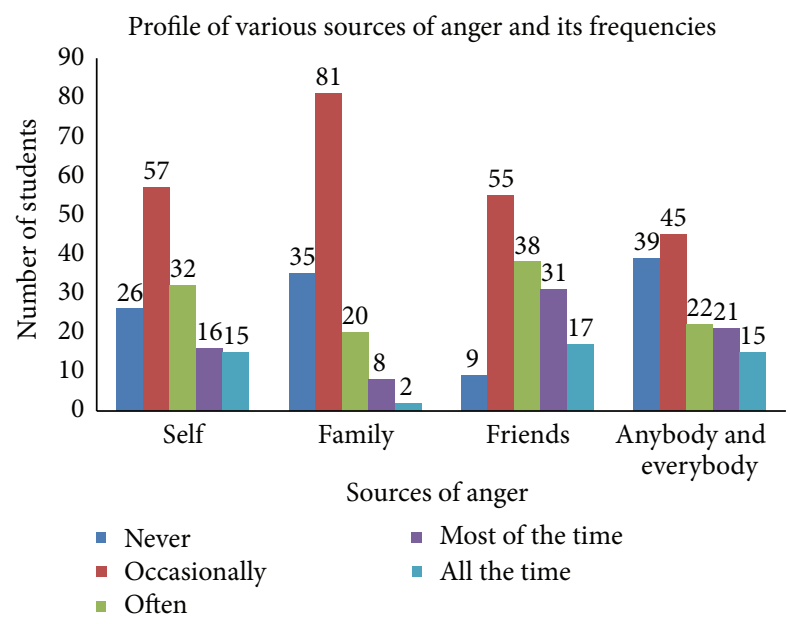

FIgURE 3: Source of anger among medical students.

relationships. 9\% of students said that it is very difficult for them to concentrate on these aspects, while 5 students (3\%) find it extremely difficult to stay focused in their work, study, and maintaining good relationships with others when they are angry [Figure 5].

Results show that $17 \%$ of students only were having minimal or no signs of depression. Few are classified under the severe and moderately severe category while the rest lie in the median range of depression [Figure 6].

3.2. Analysis Based on Correlation of Data. 39 out of the 45 students in the top 25th percentile show signs of depression, with 7 expressing minimal depression, 16 mild depression, 11 moderate depression, 3 moderately severe depression, and 2 severe depression. If we bring the lowest 25 th percentile

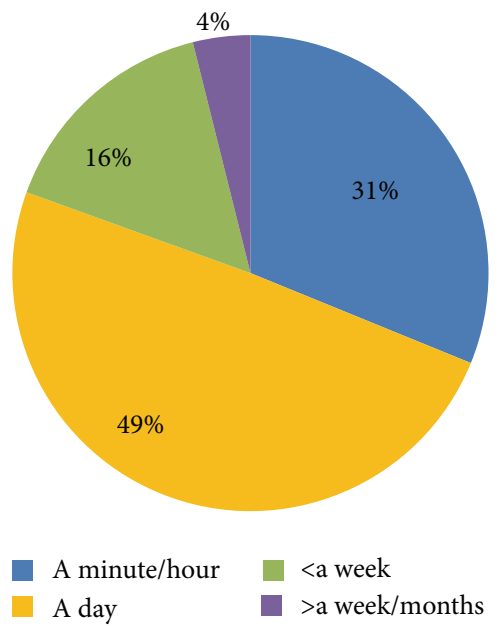

FIGURE 4: Duration of anger feelings among medical students.

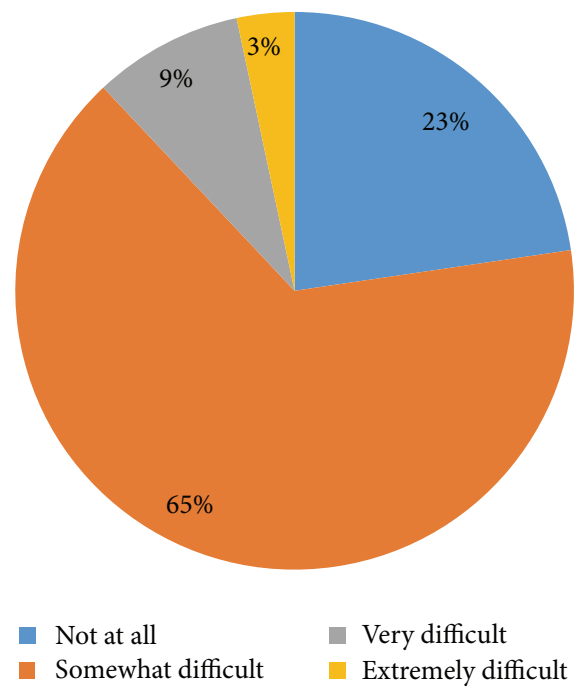

FIGURE 5: Effects of anger on work, study, and relationships as a whole.

into comparison, only 13 out of the 40 students show signs of depression, with 9 minimally depressed, 2 mildly depressed, 1 moderately depressed, and 1 severely depressed [Figure 7]. The correlation between the tendency to anger and its implication on depression among student and the circumventive abilities of anger management are revealed to be positive in terms of the student's temper and the incidence of depression among students [Figure 8].

Of the 42 students in the upper $25 \%$, that is, with good anger management skills, 28 were associated with depression, while of the 40 students who scored in the lower $25 \%$, that is, poor anger management skills, only 18 were associated with depression [Figure 9]. The results show that there is no lowering of the PHQ-9 score as the anger management technique's effectiveness rises [Figure 10]. 


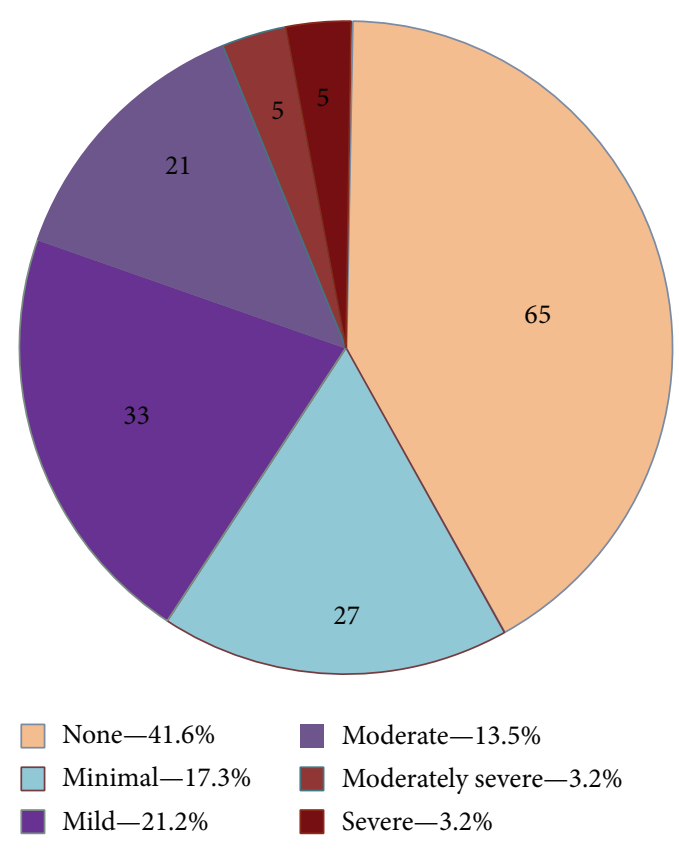

Figure 6: Number of students with signs of depression.

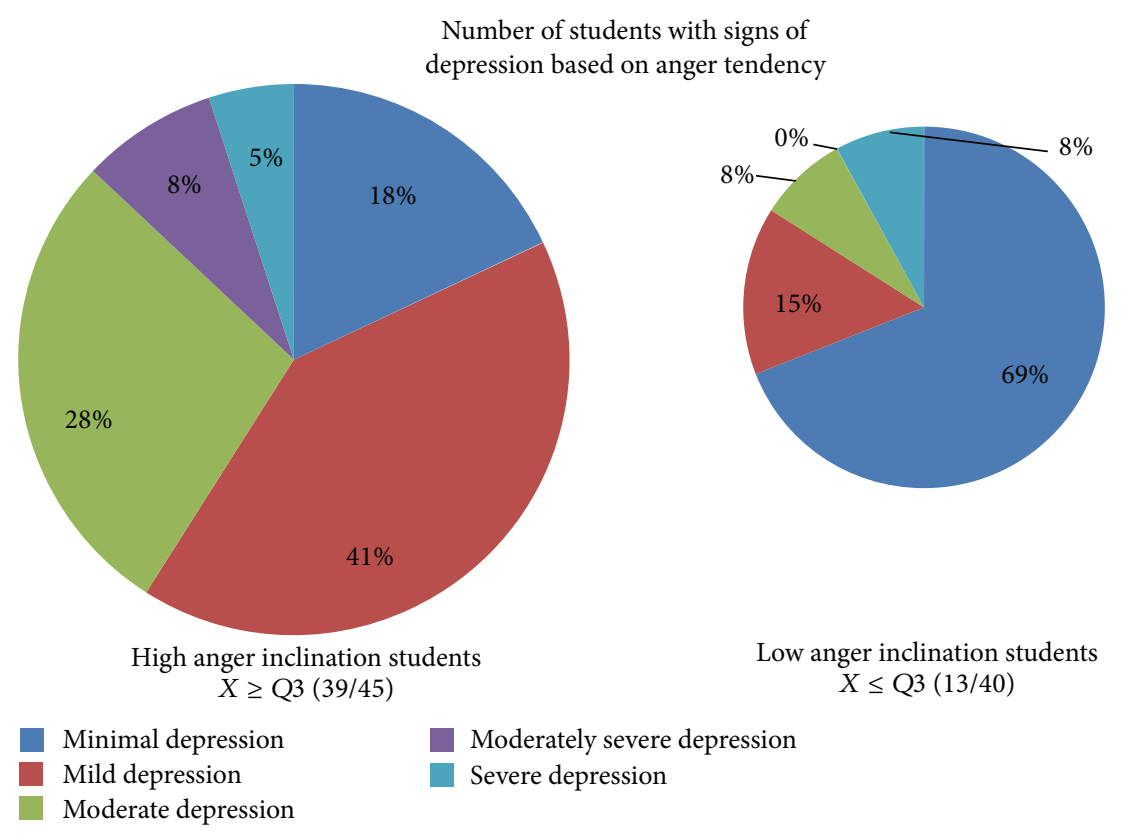

Figure 7: Anger tendency profile on depression mood.

\section{Discussion}

In the current research survey, students were requested to fill up a simplified version of the Novaco Anger Scale (NAS) and a modified version of the Patient Health Questionnaire 9 (PHQ-9) to measure their mental health score. With the exception of a few outliers, a student's inclination to be angry rises, so does the score on his modified PHQ-9. This is also evident when the numbers are put together. Students who score in the top 25th percentile on the simplified Novaco
Anger Scale, which signifies a higher tendency to anger, scored higher on the PHQ-9 questionnaire. It should also be noted that the incidents of depression among students of Melaka Manipal Medical College (MMMC) studying MBBS course are notably higher than the general populace. Majority of students who are involved in this survey were associated with some form of depression. This gives us a rate of $58.1 \%$ prevalence, which is high compared to the estimated 10\% average among Malaysians [7]. According to American College Health Association-National College 


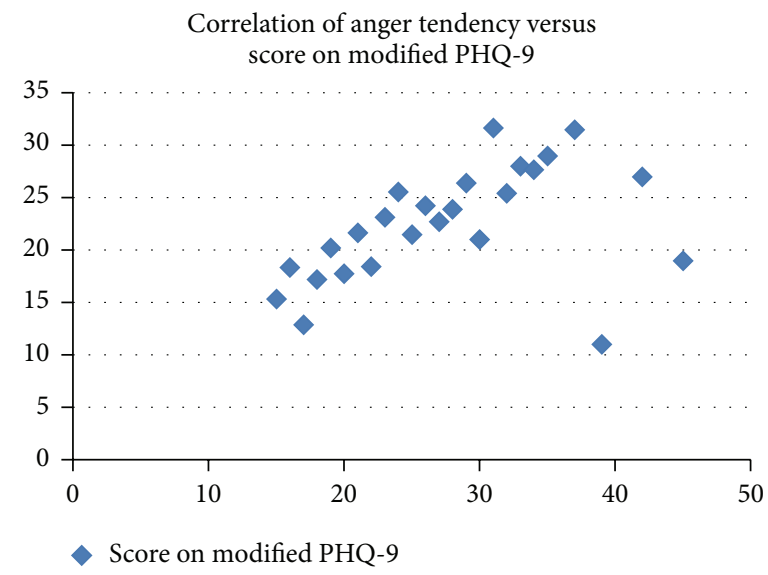

FIGURE 8: Correlation trend of anger tendency of the medical undergraduate students with respect to modified PHQ-9 score [PHQ (Patient Health Questionnaire)].

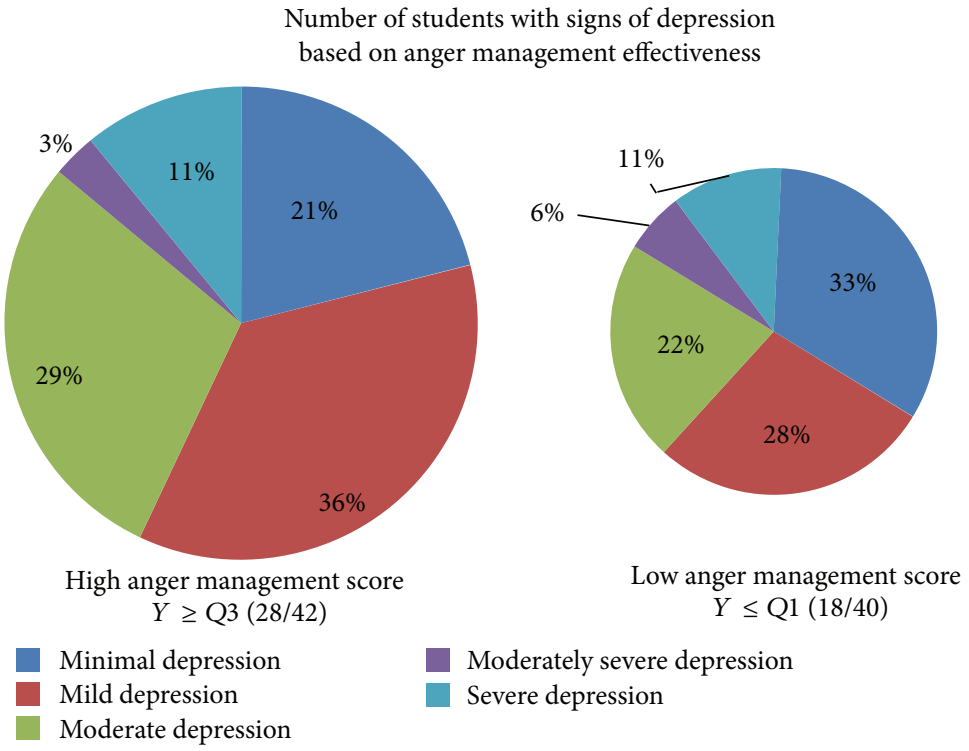

FIGURE 9: Graphic profile of signs of depression based on anger management effectiveness.

Health Assessment (ACHA-NCHA) report on Prevalence of Depression among college students, the rate of depression among college students is around $27 \%$, whereas according to that by American Medical Association-American Psychiatric Association (AMA-APA) on Physician Mortality Project Stage II, depression rate among medical professionals is around 30\%. The rate of depression in India is 35.9\% [8]. The interplay of all three factors may be significant in the high rate of depression in MMMC students. On the aspect of the circumventive abilities of anger management on depression, no perceivable pattern can be observed. Students were asked to report on their own anger management techniques and their perceived effectiveness. The score, when plotted against the results of PHQ-9, showed no lowering of the PHQ9 score as effectiveness of anger management techniques rises. It can be noted that the upper 25 th percentile have a higher incidence of depression compared to the lower 25th percentile.
It has been regarded that experiencing feel of angry is a risk factor that is often associated with negative health outcomes for an individual. It can also alarm the indication of development of certain health disorders such as hypertension and cardiovascular diseases and could also lead to headache and asthma [9]. These negative outcomes particularly affect the social skills of the students and their academic proficiency.

Enright (2009) has rightly pointed the issue that resembles the biological and behavioral disorders with the anger and reported that about $23 \%$ of children would meet the criteria for behavior disorder by the age of 16 [10]. The major setback of such issues is observed in the academic activities as attention deficit hyperactivity disorder (ADHD) with the frequency of $8 \%$ of school-aged children [11].

This research paper was also designed to evaluate the incidence of mental health issues, sources of anger, duration of anger, effects of anger, and methods of expression of 


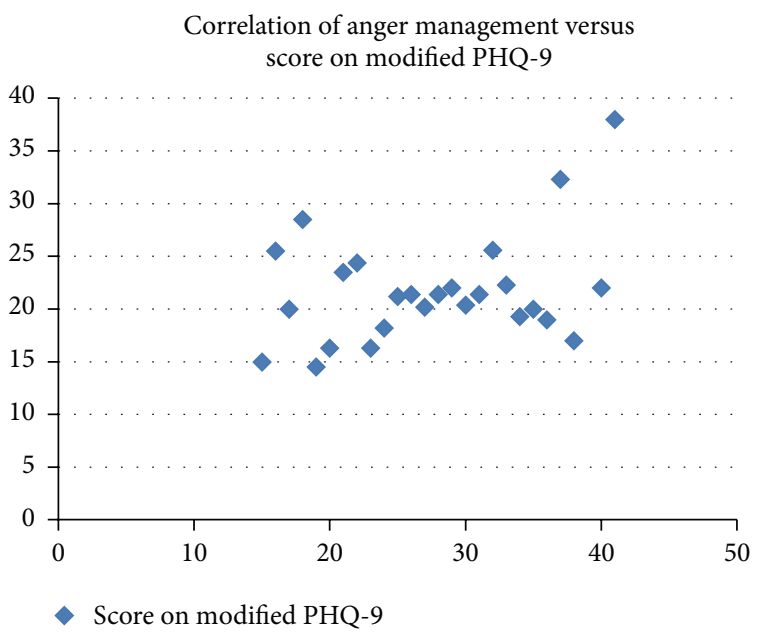

FIGURE 10: Correlation pattern of anger management on PHQ-9 [PHQ (Patient Health Questionnaire)].

second-year MBBS students studying in MMMC. On sources of anger, the participants were asked to rate the chief source of anger among a choice of self, family, friends, or everybody else. Friends were rated as the chief source of anger. This can be explained by the fact that a student's social circle consists mostly of friends. Potegal et al. stated that anger episodes vary in duration and are based on factors such as the continued presence of the offending object/person, intensity of anger, and psyche of the person [12]. However, 49\% of student population of this survey reported having anger episodes that last a day on average. This is most probably due to the fact that most of them could only recall the beginning of anger episodes when the anger is most intense and not the gradual cooling down period.

Based on anger expression and passive anger conduct, $64 \%$ of students behave as indifference and pretending to tolerate an offending item or person (dispassion). But in case of aggressive anger $16.5 \%$ of students express the anger through destructive behaviors such as substance abuse and poor eating habits. It is important to remember that the sample size of the paper is 156 students, which is quite small and highly subjected to statistical errors and luck. The reader is also advised that most MMMC students come from wellto-do families, and the results should be adjusted for a lower anger threshold and a tendency to overinflate their woes and a tendency to associate themselves with depression, which is crucial because most of the research is based on selfreporting.

\section{Conclusion}

Medical students with a higher score for their tendency towards getting angry have much poor mental health compared to the ones with lower anger tendencies. However, the results show that there is no lowering of the mental health/PHQ-9 score as the anger management technique's effectiveness rises. Notably, friends were cited as the most significant source of anger among medical students. Interestingly, many of the students have anger episodes that last a day on average, while a huge majority stated that they found it "somewhat difficult" to concentrate on their work, study, and relationships. All these may be because medical students are deprived of having sufficient time to deal with certain emotions (anger included) due to their hectic schedule. If such students are regularly monitored by the institution, their problems could be minimized by regular assessment of their nature of well-being as they are vulnerable to undergo various forms of stress especially when they are away from their hometown.

\section{Competing Interests}

The authors declare that they have no competing interests.

\section{References}

[1] D. L. Cox, S. D. Stabb, and K. H. Bruckner, Women's Anger: Clinical and Developmental Perspectives, Braun-Brumfield, Ann Arbor, Mich, USA, 1999.

[2] N. L. Stein and L. J. Levine, "The causal organisation of emotional knowledge: a developmental study," Cognition \& Emotion, vol. 3, no. 4, pp. 343-378, 1989.

[3] E. L. Feindler, S. A. Marriott, and M. Iwata, "Group anger control training for junior high school delinquents," Cognitive Therapy and Research, vol. 8, no. 3, pp. 299-311, 1984.

[4] C. D. Spielberger, State-Trait Anger Expression Inventory Professional Manual, Psychological Assessment Resources, Odessa, Fla, USA, 1996.

[5] H. C. Lench, "Anger management: diagnostic differences and treatment implications," Journal of Social and Clinical Psychology, vol. 23, no. 4, pp. 512-531, 2004.

[6] R. Novaco, Anger Control: The Development and Evaluation of an Experimental Treatment, Lexington Books, Lexington, Mass, USA, 1975.

[7] S. F. Kader Maideen, S. Mohd Sidik, L. Rampal, and F. Mukhtar, "Prevalence, associated factors and predictors of depression among adults in the community of Selangor, Malaysia," PLoS ONE, vol. 9, no. 4, Article ID e95395, 2014.

[8] E. Bromet, L. H. Andrade, I. Hwang et al., "Cross-national epidemiology of DSM-IV major depressive episode," BMC Medicine, vol. 9, no. 1, article 90, 2011.

[9] M. Rice, "Does school connectedness help to protect schoolaged children from anger and stress?" Pediatrics for Parents, vol. 25, no. 9, pp. 30-31, 2009.

[10] D. B. Enright, Angry, Defiant Youth: Origins \& Treatment, 2009, http://www.childhealing.com/articles/angrychild.php.

[11] E. Brittany, "The importance of anger management programs in elementary schools," Paper 2370, 2013, Honors Theses.

[12] M. Potegal, M. R. kosorok, and R. J. Davison, "The time course of angry behavior in the temper tantrums of young children," Annals of the New York Academy of Sciences, vol. 794, pp. 31-45, 1996. 


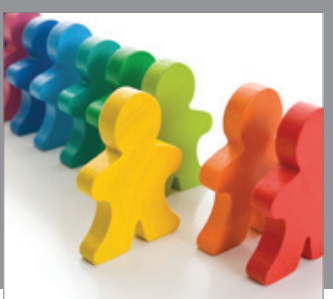

Autism

Research and Treatment
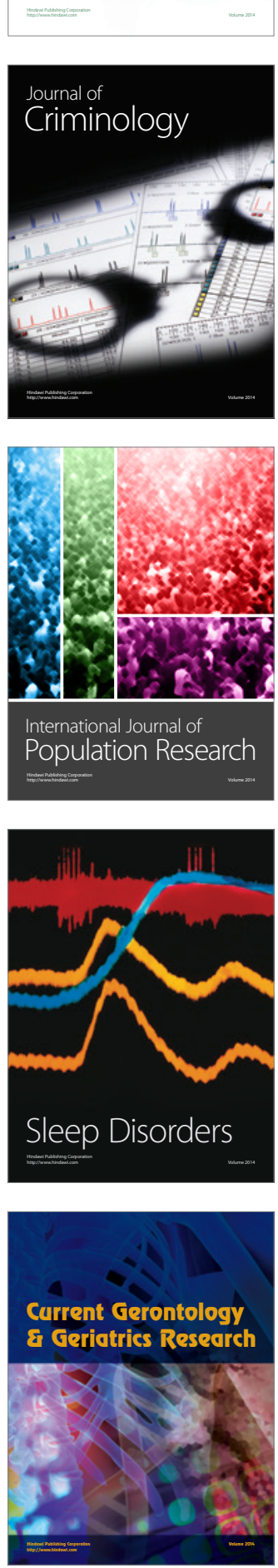

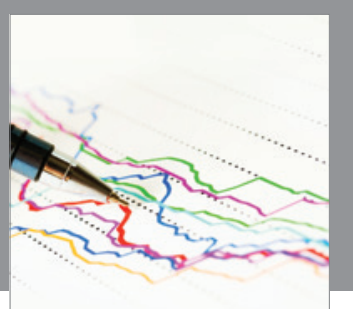

Economics

Research International
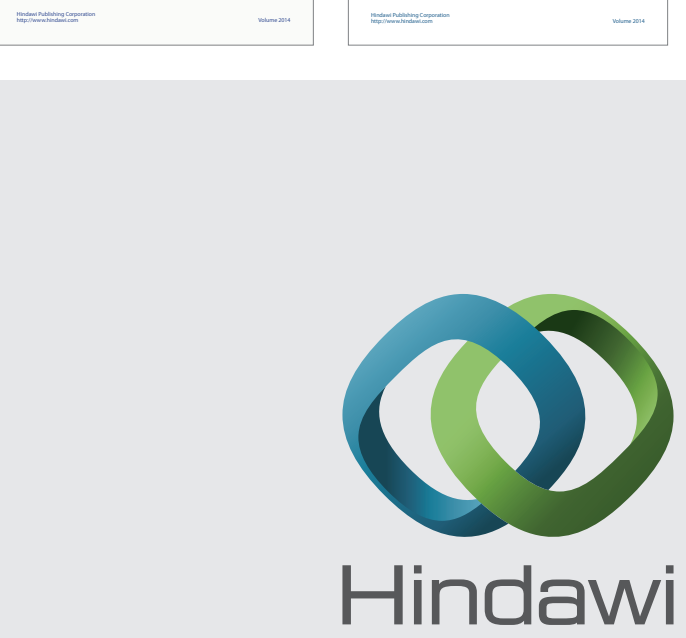

Submit your manuscripts at

http://www.hindawi.com
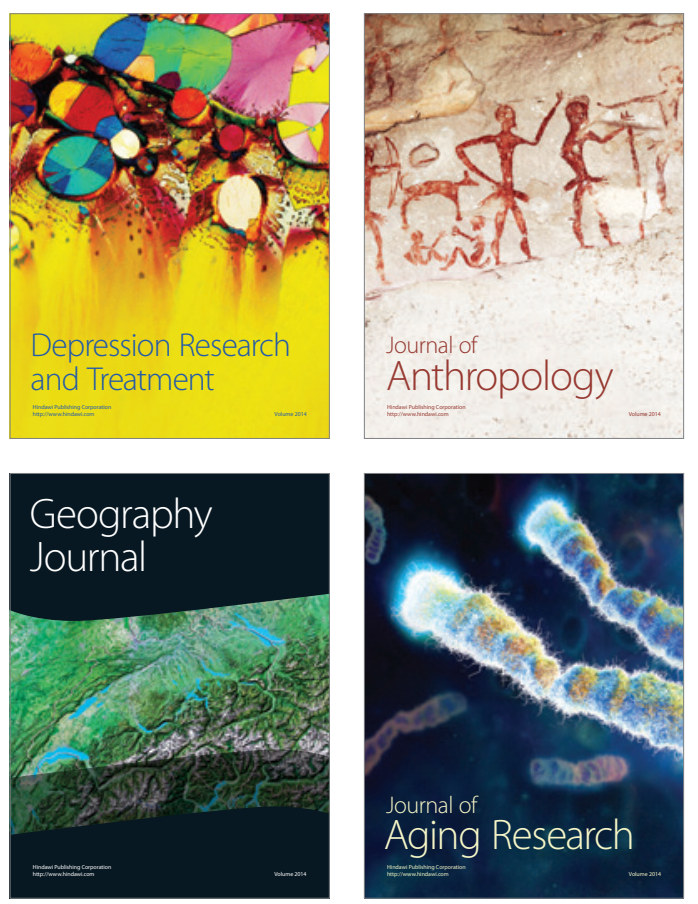
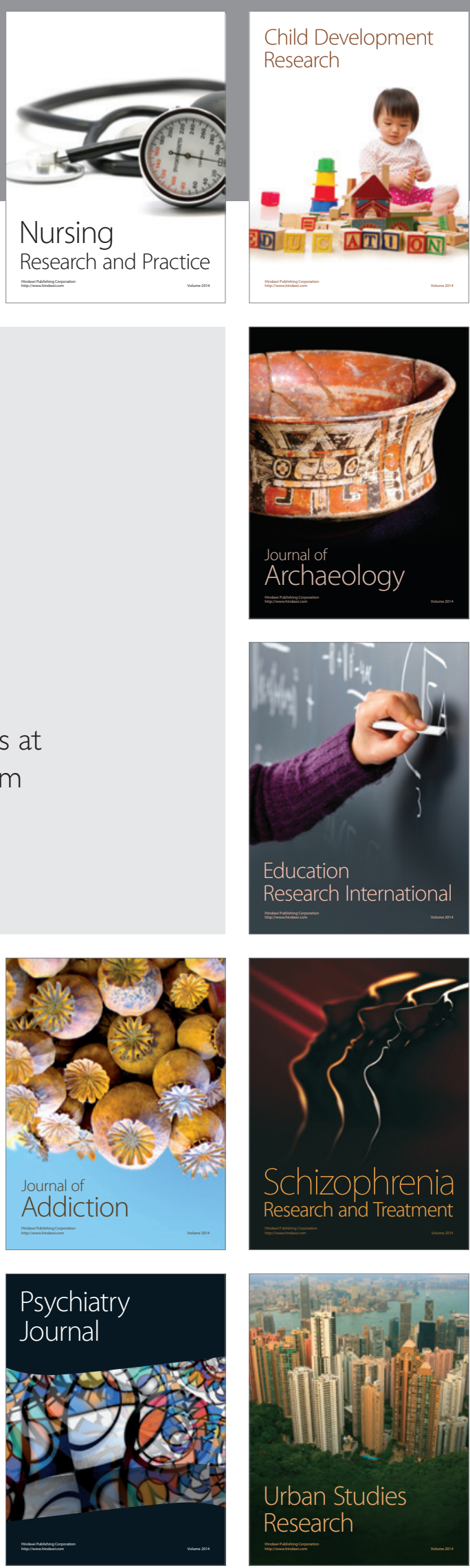